\title{
Prediction of the Frequency Response Function of a Tool Holder-Tool Assembly Based on Receptance Coupling Method
}

\author{
Xiao-Jian Xuan \\ Department of Mechanical Engineering \\ National Chin-Yi University of Technology \\ Taichung, Taiwan \\ qstar2013@gmail.com
}

Kung-Da Wu

Graduate Institute of Precision Manufacturing

National Chin-Yi University of Technology

Taichung, Taiwan

ffi85236@hotmail.com

\author{
Zhe-Hao Haung \\ Department of Mechanical Engineering \\ National Chin-Yi University of Technology \\ Taichung, Taiwan \\ 1sky05210831@gmail.com \\ Jui-Pin Hung \\ Graduate Institute of Precision Manufacturing \\ National Chin-Yi University of Technology \\ Taichung, Taiwan \\ hungjp@ncut.edu.tw
}

\begin{abstract}
Regenerative chatter has a fatal influence on machine performance in high-speed milling process. Basically, machining condition without chattering can be selected from the stability lobes diagram, which is estimated from the tool point frequency response function (FRF). However, measurements of the tool point FRF would be a complicated and time-consuming task with less efficiency. Therefore prediction of the tool point FRF is of importance for further calculation of the machining stability. This study employed the receptance coupling analysis method to predict the FRF of a tool holder-tool module, which is normally composed of substructures, tool holder and cutter with different length. In this study, the angular components of FRFs of the substructures required for coupling operation were predicted by finite element analysis, apart from the translational components measured by vibration experiments. Using this method, the effects of the overhang length of the cutter on the dynamic characteristics have been proven and successfully verified by the experimental measurements. The proposed method can be an effective way to accurately predict the dynamic behavior of the spindle tool system with different tool holder-tool modules.
\end{abstract}

Keywords-frequency response function; receptance coupling analysis method; tool holder-tool module

\section{INTRODUCTION}

According to cutting mechanics, the occurrence of chatter is considered to be caused by self-excited vibration phenomena from the interactions of dynamics of machine tool structure and machining process [1-3]. Therefore, the cause of chatter can be related to the cutting force and the structure characteristics of the machine tool structure. Since the spindle-tool holder-tool system is the most important core component of the machine tool, its dynamic performance directly affects the machining ability and precision. For a specific machine tool, to meet the required machining operation with sufficient production rate, the machining conditions of a particular cutter should be appropriately selected from the stability lobes diagram of the spindle tool system [4-6]. Generally, the machining stability of a cutter can be determined from the measured FRFs. However this would be a complicated and time-consuming task, with less efficiency. A number of studies based on the receptance coupling substructure analysis (RCSA) method have been performed to predict the tool point frequency response functions and hence machining stability [5-8].

In the RCSA approach for the machine spindle tool system, the spindle-holder tool module is considered as three separate components: spindle, tool and holder, and the frequency responses of these components are required parameters for the coupling operation to predict the tool point FRF. However, in practice, only the frequency responses of the linear displacement to the force can be directly measured through vibration tests. The other frequency responses associated with the linear or rotational displacement to the force or moment were obtained from analytical solution by modeling the spindle tool assembly as the Euler-Bernoulli or Timoshenko beam model [9-11]. Another approach based on first-order backward finite difference analysis was applied to derive the frequency responses of the rotational displacement-to-force from the measured linear FRFs [12-14]. In this approach, two linear displacement-to-force FRFs were measured at a specific point, such as tool tip, and its neighboring point at certain distance. The accuracy depends greatly on the distance between the two measured points [13]. Another key point for accurate coupling operation is the modeling of the coupling interface within the assembled structures, which have been verified to affect tool point FRF [11, 15-17], while the contact characteristics of the tool-holder interface and tool holder-spindle nose cannot be 
measured experimentally or calculated analytically. Therefore, identification approaches in different ways were proposed to identify the contact properties of the elastic interface from the experimentally measured FRFs and the analytically derived FRFs [17], which was further introduced in the receptance coupling operation of the assembled structures. In this study, the assembled module of tool holder and tool was employed for predicting the FRFs based on the receptance coupling operation of the individual compliance matrix of each substructure. The effect of the tool length on the tool point FRF was investigated. To lessen the inaccuracy of the approximation estimation of the compliance components associated with the rotational displacement or applied moment, we employed the finite element method to calculate the FRFs of the linear displacement-to-moment or the rotational displacement-toforce of the substructure component such as the holder and cutter. Also, the interface characteristics between the cutter and tool holder were identified by inverse coupling from experimental measurements on the tool holder-tool assemble, which was then implemented into the developed algorithm to calculate the dynamic response of the tool-holder-tool system when a tool with different length was used. The predicted tool end FRFs were compared with the experimental measurements conducted on the physical modules.

\section{BASIC THEORY OF RECEPTANCE COUPLING METHOD}

In this study, receptance coupling method was used to predict the frequency response functions of a tool holder-cutter (assembled structure AB) from those of the cutter (substructure A) and tool holder (substructure B) with coupled effects of the bonding interface between the substructures $A$ and $B$. As shown in Figure 1, the assembled structure $A B$ is formed by inserting the cutter into the collet of the holder. For the cutter (substructure A), the relationship between the displacements of points $1, A_{2}$ and forces $F_{1}, F_{2}$ can be expressed as

$$
\left\{\begin{array}{c}
\mathrm{X}_{1} \\
\mathrm{XA}_{2}
\end{array}\right\}=\left[\begin{array}{ll}
\mathrm{HA}_{11} & \mathrm{HA}_{12} \\
\mathrm{HA}_{21} & \mathrm{HA}_{22}
\end{array}\right]\left\{\begin{array}{c}
\mathrm{F}_{1} \\
\mathrm{FA}_{2}
\end{array}\right\}
$$

For the tool holder (substructure $\mathrm{B}$ ), the relationship between the displacement of point $\mathrm{B}_{2}$ and force $\mathrm{FB}_{2}$ is:

$$
\left\{\mathrm{XB}_{2}\right\}=\left[\mathrm{HB}_{22}\right]\left\{\mathrm{FB}_{2}\right\}
$$

When the cutter is combined with the tool holder, we have:

$$
\mathrm{F}_{2}=\mathrm{F}_{\mathrm{A} 2}+\mathrm{F}_{\mathrm{B} 2}, \quad \mathrm{X}_{2}=\mathrm{X}_{\mathrm{A} 2}=\mathrm{X}_{\mathrm{B} 2}
$$

The displacement of point 1 caused by the force $F_{1}$ can be obtained as follows:

$\mathrm{G}_{11}=\frac{\mathrm{X}_{1}}{\mathrm{~F}_{1}}=\mathrm{HA}_{11}-\mathrm{HA}_{12}\left(\mathrm{HA}_{22}+\mathrm{HB}_{22}\right)^{-1} \mathrm{HA}_{21}$

where $\mathrm{H}_{2}=\mathrm{HA}_{22}+\mathrm{HB}_{22}$, representing the coupled term of substructure $A$ and substructure $B$ and $G_{11}$ is the frequency response function at the tool end due to the excitation $F_{1}$.

Actually, the displacement components measured at each point on the structure include the linear translation displacement $(\mathrm{x})$ and the angular displacement $(\theta)$, which are caused by the force $\left(f_{1}\right)$ and moment $\left(M_{1}\right)$, respectively. The generalized relationship between the displacement vector $\left\{\mathrm{X}_{1}\right\}$ and force vector $\left\{\mathrm{F}_{1}\right\}$ can be expressed as follows:

$$
\begin{aligned}
& \left\{\mathrm{X}_{1}\right\}=\left\{\begin{array}{l}
\mathrm{x}_{1} \\
\theta_{1}
\end{array}\right\} ;\left\{\mathrm{F}_{1}\right\}=\left\{\begin{array}{c}
\mathrm{f}_{1} \\
\mathrm{M}_{1}
\end{array}\right\} \\
& \left\{\begin{array}{c}
x_{1} \\
\theta_{1}
\end{array}\right\}=\left[H \mathrm{~A}_{11}\right]\left\{\begin{array}{c}
f_{1} \\
M_{1}
\end{array}\right\}=\left[\begin{array}{ll}
H \mathrm{a}_{11} & L \mathrm{a}_{11} \\
N \mathrm{a}_{11} & P \mathrm{a}_{11}
\end{array}\right]_{A}\left\{\begin{array}{c}
f_{1} \\
M_{1}
\end{array}\right\} \\
& H \mathrm{a}_{11}=\frac{x_{1}}{f_{1}}, L \mathrm{a}_{11}=\frac{x_{1}}{M_{1}} ; N \mathrm{a}_{11}=\frac{\theta_{1}}{f_{1}} ; P \mathrm{a}_{11}=\frac{\theta_{1}}{M_{1}}
\end{aligned}
$$

where $\left[\mathrm{HA}_{11}\right]$ represents the frequency responses matrix or component receptance matrix of the structure. Considering the elastic interface between the cutter (A) and tool holder (B), the coupled effect should be included in (4) through the interface characteristics matrix [9]:

$\left[K_{s}\right]=\left[\begin{array}{cc}K_{x f}+i_{w} C_{x f} & K_{\theta f}+i_{w} C_{\theta f} \\ K_{x M}+i w C_{x M} & K_{\theta M}+i w C_{\theta M}\end{array}\right]$

where $\mathrm{K}_{\mathrm{xf}}, \mathrm{K}_{\theta \mathrm{f}}, \mathrm{K}_{\mathrm{xm}}$ and $\mathrm{K}_{\theta \mathrm{m}}$ are the stiffness of the contact interface under transverse force $f$ and bending moment $\mathrm{M}$, and $\mathrm{C}_{\mathrm{xf}}, \mathrm{C}_{\theta \mathrm{f}}, \mathrm{C}_{\mathrm{xm}}$ and $\mathrm{C}_{\theta \mathrm{m}}$ are damping coefficients of contact interface.

When the contact characteristics are included in receptance coupling operation, the coupling equation for prediction of the compliance matrix of structure assembly becomes

$$
\begin{aligned}
& {\left[\mathrm{GT}_{11}\right]=\left[\left[\mathrm{HA}_{11}\right]-\left[\mathrm{HA}_{12}\right] *\left[\mathrm{H}_{2}\right]^{-1} *\left[\mathrm{HA}_{21}\right]\right]} \\
& \text { in which }\left[\mathrm{H}_{2}\right]=\left[\mathrm{HA}_{22}\right]+\left[\mathrm{HB}_{22}\right]+\left[\mathrm{K}_{\mathrm{s}}\right]^{-1}
\end{aligned}
$$

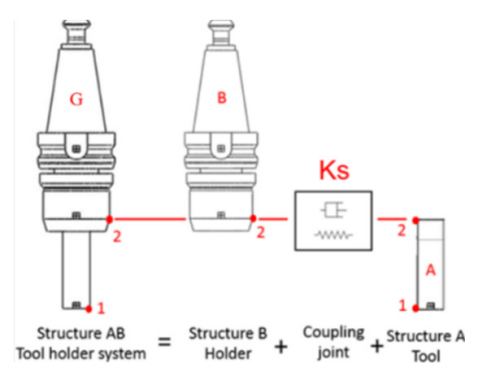

Fig. 1. Schematic of the substructure coupling

\section{EXPERIMENTAL MEASUREMENT OF FRFS}

The FRFs associated with the linear displacement-to-force required for receptance coupling operation were measured by vibration tests, including tool holder (BBT40), cutter and tool holder-cutter module respectively. In order to exclude the influences of the cutter geometry, cylindrical rods with diameter of $20 \mathrm{~mm}$ were used, which were made in length of $110,120,130,140$ and $150 \mathrm{~mm}$. In the assembled module, each rod was clamped in the holder collet at the same length of $50 \mathrm{~mm}$, which had a different overhang length of $60,70,80,90$ and $100 \mathrm{~mm}$. The experimental configurations for different components are illustrated in Figure 2. As shown, the testing rod was suspended by two wire ropes and excited at one end (point 1) by the impact hammer. Two accelerometers were mounted on both ends, point 1 and point 2 to measure the vibration signals. The FRFs were then extracted from the measured vibration spectrum. The measured FRFs of the rods are illustrated in Figure 3, and were termed as $\mathrm{Ha}_{11}$. The results 
show that the dominant natural frequency of the cylindrical rod decreases with increasing length and the compliance increases with increasing length. The FRFs of the tool holder, termed as $H b_{22}$, were measured in similar way, as shown in Figure 4. The tool holder shows a higher frequency, about $7750 \mathrm{~Hz}$ and lower compliance, about $0.011 \mathrm{um} / \mathrm{N}$. The FRFs, termed as $G_{11}$, of the assembled structure of the tool holder and rod of different lengths are illustrated in Figure 5 for comparison. It is found that the assembled tool holder-rod module with short overhang length shows higher frequency and lower compliance when compared to the assembled module with longer overhang length. For example, in the case of the rod with length of $150 \mathrm{~mm}$, the assembled module shows a maximum compliance of $9.8 \mathrm{um} / \mathrm{N}$ at frequency of $1500 \mathrm{~Hz}$. In the case of rod with length of $120 \mathrm{~mm}$, the maximum compliance of the tool holderrod assembly is $3.35 \mathrm{um} / \mathrm{N}$, occurring at $2250 \mathrm{~Hz}$. This result shows that the tool holder with a longer tool behaves more complaint than with a shorter tool.

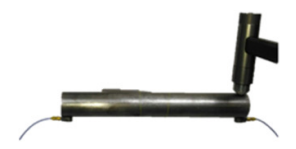

(a) Cylindrical rod (A)

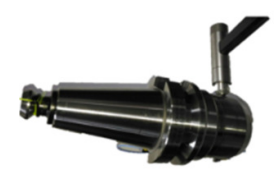

(b) Tool holder (B)

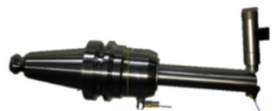

(c) Tool holder and rod assembly (AB)

Fig. 2. Vibration tests of tool holder and tool components.

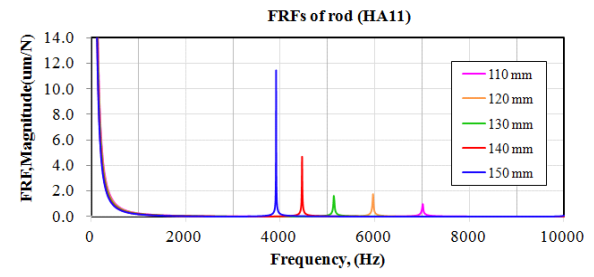

Fig. 3. Measured FRFs of cylindrical rod with different lengths

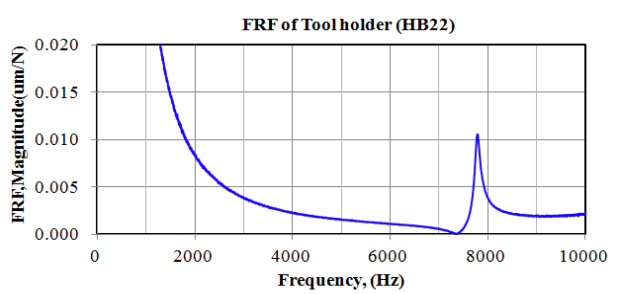

Fig. 4. Measured FRF of tool holder.

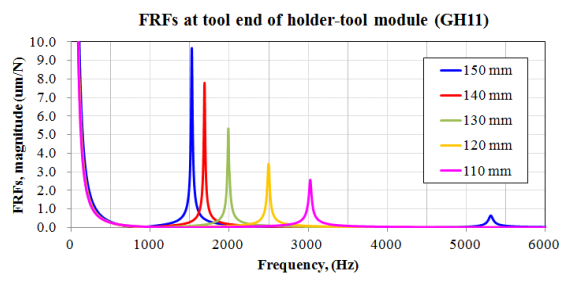

Fig. 5. Measured FRFs of tool holder with tool in different length

\section{PREDICTIONS OF FRFS OF TOOL HOLDER AND TOOL ASSEMBLY}

\section{A. Estimation of the Receptance Compliance Matrix}

As demonstrated above, the direct or cross compliance components in receptance matrix such as the $H a_{11}$ and $H a_{12}$, can be obtained from vibration test. However, the other terms such as the $L a_{11}=\left(x_{1} / M_{1}\right), N a_{11}=\left(\theta_{1} / f_{1}\right)$ and $P a_{11}=\left(\theta_{1} / M_{1}\right)$ can only be obtained by numerical approaches $[11,12]$, but with less accuracy. In this study, the components $L a_{i j}$ are predicted by finite element analysis and then are used to derive $N a_{i j}$ and $P a_{i j}$. To this, finite element models of the substructures and assembled structures were created for analysis, as shown in Figure 6, including the holder, cutter (cylindrical rod) and holder-rod assembled model. The material properties of the structure components are $\rho=7860 \mathrm{~kg} / \mathrm{m}^{3}$, Young's modulus $\mathrm{E}=200 \mathrm{GPa}$ and Poisson's ratio $\mu=0.3$. The interface between the collet of the holder and rod was modeled with surface to surface spring elements in radial and rotational directions with appropriate contact stiffness. The models were validated by comparing the frequency response functions obtained from finite element prediction and experimental measurements. According to harmonic analysis, the predicted frequency response functions, termed $H a_{11}, H b_{22}$ and $G l_{11}$, associated with tool holder, tool and holder-tool assembly, respectively, are illustrated in Figure 7. It is apparent that the peak compliance and the resonant frequencies for the three components agree well with the measurements. Taking tool holder-tool assembly as an example, the differences in modal frequency and maximum compliance between finite element prediction and measurements are $1.1 \%$ and $2.2 \%$, respectively. From the comparisons, the linear and rotational stiffness of the interface between tool holder collet and rod were identified as $3.03 \times 10^{8} \mathrm{~N} / \mathrm{m}$ and $3.25 \times 10^{3} \mathrm{~N}-\mathrm{m} / \mathrm{rad}$, respectively.

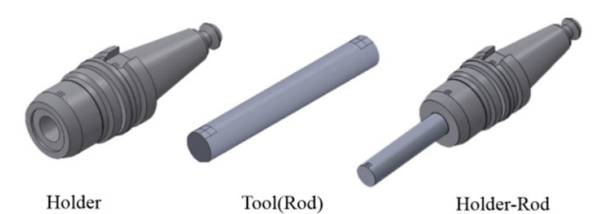

(a) Solid model of tool holder and tool

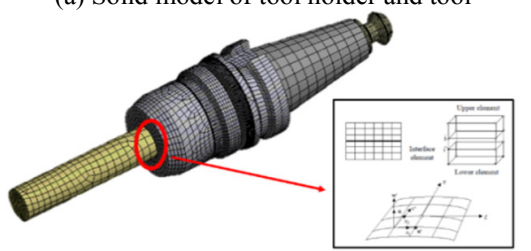

(b) Finite element model

Fig. 6. Finite element model of tool holder-tool model and modeling of the contact interface

With these validated models, the frequency response functions, such as $H a_{11}$ and $L a_{11}$, associated with the linear displacements to the applied force or moment can be obtained by performing the harmonic analysis. As shown in Figure 8, for rod model (substructure A), the direct compliance component $L a_{11}$, can be computed from FRFs of linear displacement $\mathrm{x}_{1}$ under excitation of the moment $\mathrm{M}_{1}$ and the cross component 
$L a_{21}$ can be computed from FRFs of linear displacement $\mathrm{x}_{2}$ under excitation of the moment $\mathrm{M}_{1}$. In similar ways, the compliance components $L b_{22}$ of the tool holder (substructure B) and $G l_{11}$ of the holder-rod module (assembled structure $\mathrm{AB}$ ) can be obtained from the harmonic analysis.

(a)
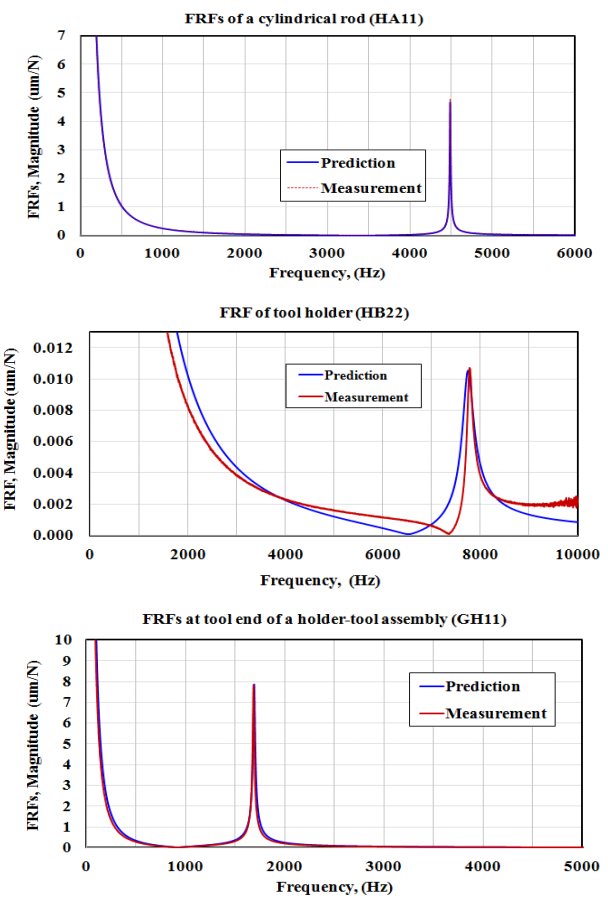

Fig. 7. Comparisons of the predicted and measured FRFs of the tool, tool holder and the assembled tool holder
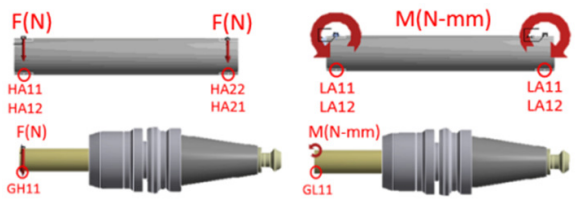

Fig. 8. Harmonic analysis for FRFs $H x_{i j}$ and $L x_{i j}$ of the cylindrical rod and tool holder-tool assembly prediction.

\section{B. Prediction Results and Discussion}

In receptance coupling operation, the compliance matrices of the individual substructures such as $\left[\mathrm{HA}_{11}\right],\left[\mathrm{HA}_{12}\right]$ and $\left[\mathrm{HB}_{22}\right]$ in (9) are required. The general form of the compliance matrix is composed of four components, as indicated in (6) and (7). For each substructure, the direct component of linear displacement-to-force $\left(H a_{11}\right)$ can be measured through the vibration tests, and the $L a_{11}$ can be obtained by finite element predictions, $N a_{11}$ and $P a_{11}$ are obtained by numerical approach employed in [14]. Besides, the dynamic characteristic matrix $[\mathrm{Ks}]$ of the bonded interface between tool holder and cutter should be introduced in coupling operation. However, these parameters are unavailable in practice and can only be identified through parameter identification from experimental measurements. This can be done by inverse coupling operation from (8), that is:

$$
\left[\mathrm{K}_{\mathrm{sh}}\right]=\left[\left[\mathrm{HA}_{12}\right]^{-1} \times\left(\left[\mathrm{GT}_{11}\right]-\left[\mathrm{HA}_{11}\right]\right)^{-1} \times\left[\mathrm{HA}_{21}\right]^{-1}-\left[\mathrm{HA}_{22}\right]-\left[\mathrm{HB}_{22}\right]\right]^{-1}
$$

In which the terms $\left[\mathrm{HA}_{11}\right],\left[\mathrm{HA}_{21}\right],\left[\mathrm{HA}_{12}\right]$ and $\left[\mathrm{HA}_{22}\right]$ are compliance matrices of the FRFs associated with the cylindrical rod, $\left[\mathrm{HB}_{22}\right]$ is the compliance matrix of FRFs associated with the tool holder and $\left[\mathrm{GT}_{11}\right]$ is compliance matrix associated with the tool holder-rod assembled module. In this study, an assembled module of a tool holder with rod length of $150 \mathrm{~mm}$ was used as the reference for inverse operation of receptance coupling analysis to identify the dynamic interface characteristics. By substituting the receptance compliance matrices associated with this assembled structures into (10), the dynamic interface characteristics between tool holder and cylindrical rod at the dominant mode of $1520 \mathrm{~Hz}$ were quantified and listed in Table I. The linear translational stiffness and damping coefficient of the interface corresponding to the dominant mode are $1.2587 \times 10^{7} \mathrm{~N} / \mathrm{m}$ and $3378.1 \mathrm{~N} \cdot \mathrm{s} / \mathrm{m}$, respectively. The interface contact stiffness and damping coefficient corresponding to the angular components are $3.8978 \times 10^{5} \mathrm{Nm} / \mathrm{rad}$ and $11.828 \mathrm{Nm} \cdot \mathrm{s} / \mathrm{rad}$ respectively. Based on the receptance coupling analysis incorporated with the interface characteristics, the tool end frequency response functions of the assembled tool holder-tool module with different rod length can be obtained.

TABLE I. HOLDER-TOOL INTERFACE DYNAMIC CONTACT CHARACTERISTICS.

\begin{tabular}{|c|c|}
\hline Linear displacement to force stiffness $(\mathrm{N} / \mathrm{m})$ & $1.2587 \times 107$ \\
\hline Linear displacement to force damping $(\mathrm{N} \cdot \mathrm{s} / \mathrm{m})$ & 3378.1 \\
\hline Linear displacement to moment stiffness $(\mathrm{N} / \mathrm{m})$ & $1.5740 \times 106$ \\
\hline Linear displacement to moment damping $(\mathrm{Nm} \cdot \mathrm{s} / \mathrm{m})$ & 117.50 \\
\hline Angular displacement to force stiffness $(\mathrm{N} / \mathrm{rad})$ & $1.4474 \times 106$ \\
\hline Angular displacement to force damping $(\mathrm{N} \cdot \mathrm{s} / \mathrm{rad})$ & 13.811 \\
\hline Angular displacement to moment stiffness $(\mathrm{Nm} / \mathrm{rad})$ & $3.8978 \times 105$ \\
\hline Angular displacement to moment damping $(\mathrm{Nm} \cdot \mathrm{s} / \mathrm{rad})$ & 11.828 \\
\hline
\end{tabular}

Figure 9 shows the tool point FRFs $\left(\mathrm{GH}_{11}\right)$ predicted for the tool holder with a rod in length of 110, 120, 130 and 140mm. It is found that the predictions are well consistent with the measurements in vibration test of a physical unit. For the four different assemblies, the dominant frequency of the tool holdertool assembly predicted by receptance coupling operation is very close to the measured frequency, with difference less than $1.0 \%$, which clearly demonstrates that the tool holder and tool interface dominates the vibration behavior of the assembled structure, while the difference of the predicted and measured tool compliance is about $2.0 \%$. Basically, the difference can be ascribed to the fact that the real contact characteristics including the contact stiffness and interface damping property could be slightly affected to change with tool length. However, as noted above, the contact characteristics of the holder-tool interface identified in this study are appropriate for modeling the physical tool holder system. Overall, the receptance coupling method presented in this paper works very successfully.

\section{CONCLUSIONS}

This paper presents predictions of the FRFs of the tool holder-tool assembly by using the receptance coupling operation method. In this proposed method, the compliance components associated with the linear displacement to forces were directly measured by conducting the vibration test on the physical structures while other components in linear and 
angular displacements were computed by finite element approach and numerical approximation.

(a)

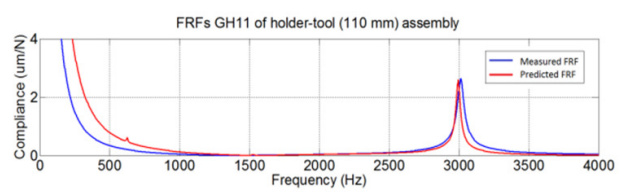

(b)
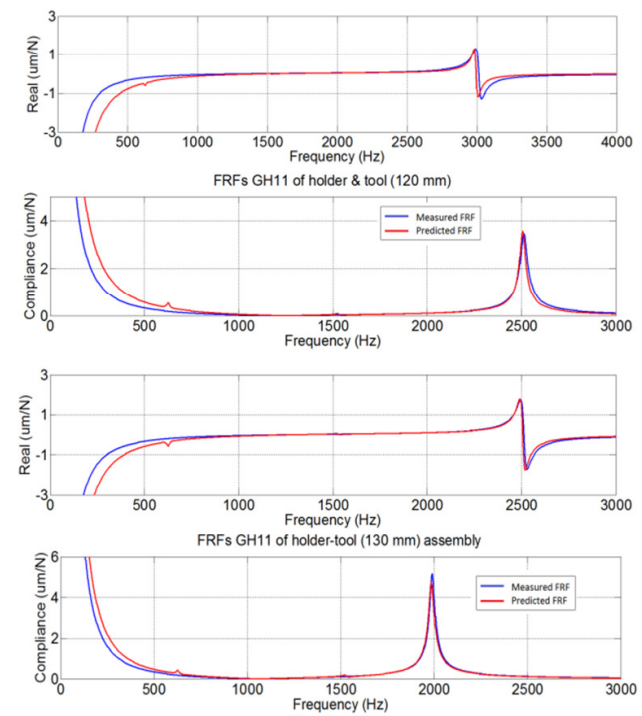

(c)
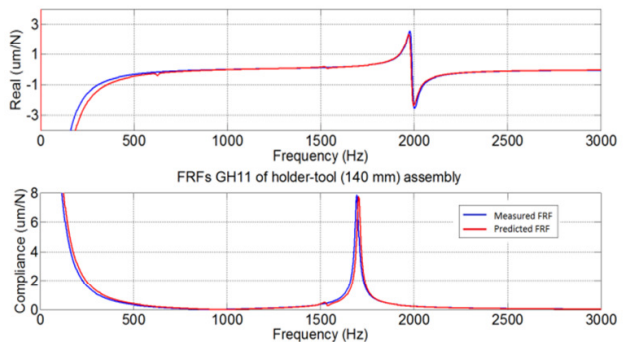

(d)

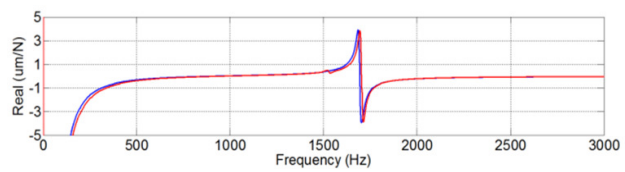

Fig. 9. Predicted tool end FRFs of tool holder and tool assembly with different tool lengths: (a) $110 \mathrm{~mm}$, (b) $120 \mathrm{~mm}$, (c) $130 \mathrm{~mm}$ and (d) $140 \mathrm{~mm}$.

The interface characteristics identified by inverse receptance coupling from experimental measurements have been used to couple the frequency responses of the substructures of holder and tool. Comparisons of the FRFs obtained from predictions and measurements clearly demonstrate that the contact characteristics of the holder-tool interface identified in this study are appropriate for modeling the physical tool holder system, which can accurately predict vibration behavior of the tool holder-tool assemblies with different tool length. As a whole, the receptance coupling method presented in this study can be applied for the prediction of the tool point FRF of a spindle tool system.

\section{ACKNOWLEDGEMENT}

Authors acknowledge the support for this work provided by the Intelligent Machinery Technology Center, Industrial Technology Research Institute and National Science Council in Taiwan through project number MOST105-2622-E-167-011CC3.

\section{REFERENCES}

[1] J. Tlusty, M. Polacek, "The Stability of Machine Tools against Self Excited Vibrations in Machining", in: International Research in Production Engineering, pp. 465-474, ASME, 1963

[2] J. Tlusty, "Dynamics of high-speed milling", Journal of Engineering for Industry, Vol. 108, No. 2, pp. 59-67, 1986

[3] F. Koenisberger, J. Tlusty, Machine Tool Structures-Vol. I: Stability Against Chatter, Pergamon, Englewood Cliffs, 1967

[4] I. Minis, R. Yanushevsky, A. Tembo, R. Hocken, "Analysis of linear and nonlinear chatter in milling", CIRP Annals-Manufacturing Technology, Vol. 39, No. 1, pp. 459-462, 1990

[5] T. L. Schmitz, R. R. Donalson, "Predicting high-speed machining dynamics by substructure analysis", CIRP Annals-Manufacturing Technology, Vol. 49, No.1, pp. 303-308, 2000

[6] T. Schmitz, M. Davies, M. Kennedy, "Tool point frequency response prediction for high-speed machining by RCSA", Journal of Manufacturing Science and Engineering, Vol. 123, No. 4, pp. 700-707, 2001

[7] T. L. Schmitz, T. J. Burns, "Receptance coupling for high-speed machining dynamics prediction", 21st Conference \& Exposition on Structural Dynamics, Kissimmee, FL, USA, February 3-6, 2003

[8] O. Ozsahin, Y. Altintas, "Prediction of frequency response function (FRF) of asymmetric tools from the analytical coupling of spindle and beam models of holder and tool", International Journal of Machine Tools and Manufacture, Vol. 92, pp. 31-40, 2015

[9] A. Erturk, H. N. Ozguven, E. Budak, "Analytical modeling of spindletool dynamics on machine tools using Timoshenko beam model and receptance coupling for the prediction of tool point FRF", International Journal of Machine Tools and Manufacture, Vol. 46. No. 15, pp. 19011912,2006

[10] O. Ozsahin, A. Erturk, H. N. Ozguven, E. Budak, “A closed-form approach for identification of dynamical contact parameters in spindleholder-tool assemblies", International Journal of Machine Tools and Manufacture, Vol. 49, No. 1, pp. 25-35, 2009

[11] U. V. Kumar, T. L Schmitz, "Spindle dynamics identification for receptance coupling substructure analysis", Precision Engineering, Vol. 32, No. 3, pp. 435-443, 2012

[12] T. L. Schmitz, G. S. Duncan, "Three-component receptance coupling substructure analysis for tool point dynamics prediction", Journal of Manufacturing Science and Engineering, Vol. 127, No. 4, pp. 781-790, 2005

[13] P. Albertelli, M. Goletti, M. A. Monno, “A new receptance coupling substructure analysis methodology to improve chatter free cutting conditions prediction", International Journal of Machine Tools and Manufacture, Vol. 72, pp. 16-24, 2013

[14] T. L. Schmitz, M. A. Davies, K. Medicus, J. Snyder, "Improving highspeed machining material removal rates by rapid dynamic analysis", CIRP Annals-Manufacturing Technology, Vo. 50, No. 1, pp. 263-268, 2001

[15] S. S. Park, Y. Altintas, M. Movahhedy, "Receptance coupling for end mills", International Journal of Machine Tools and Manufacture, Vol. 43 No.9. pp. 889-896, 2003

[16] A. Erturk, H. N. Ozguven, E. Budak, "Effect analysis of bearing and interface dynamics on tool point FRF for chatter stability in machine tools by using a new analytical model for spindle-tool assemblies", International Journal of Machine Tools and Manufacture, Vol. 47, No. 1, pp. 23-32, 2007

[17] E. Budak, A. Erturk, H. N. Ozguven, "A modeling approach for analysis and improvement of spindle-holder-tool assembly dynamics", CIRP Annals-Manufacturing Technology, Vol. 55, No. 1, pp. 369-372, 2006 